\title{
The APEC Digital Hub-WONCA Collaborative Framework on Integration of Mental Health into Primary Care in the Asia Pacific
}

This article was published in the following Dove Press journal: Journal of Multidisciplinary Healthcare

\author{
Chris Dowrick ${ }^{1,2}$ \\ Ryuki Kassai $\mathbb{D}^{2,3}$ \\ Cindy LK Lam $\mathbb{D}^{2,4}$ \\ Raymond W Lam (iD) ${ }^{5,6}$ \\ Garth Manning (1D ${ }^{2}$ \\ Jill Murphy, \\ Chee $\mathrm{H} \mathrm{Ng} \mathbb{D}^{7,8}$ \\ Chandramani \\ Thuraisingham $\mathbb{D}^{2,9}$ \\ 'Department of Primary Care and Public \\ Health, University of Liverpool, \\ Liverpool, UK; ${ }^{2}$ World Organization of \\ Family Doctors (WONCA), Bangkok, \\ Thailand; ${ }^{3}$ Department of Community \\ and Family Medicine, Fukushima Medical \\ University, Fukushima, Japan; \\ ${ }^{4}$ Department of Family Medicine \& \\ Primary Care, The University of \\ Hong Kong, Hong Kong; ${ }^{5}$ Department of \\ Psychiatry, University of British \\ Columbia, Vancouver, BC, Canada; ${ }^{6}$ Asia- \\ Pacific Economic Cooperation (APEC) \\ Digital Hub for Mental Health, Vancouver, \\ BC, Canada; ${ }^{7}$ Department of Psychiatry, \\ University of Melbourne, Melbourne, \\ Australia; ${ }^{8}$ Asia-Pacific Economic \\ Cooperation(APEC) Digital Hub for \\ Mental Health, Melbourne, Australia; \\ ${ }^{9}$ Department of Family Medicine, \\ International Medical University, Kuala \\ Lumpur, Malaysia
}

Correspondence: Cindy LK Lam; Chee $\mathrm{H} \mathrm{Ng}$

Email clklam@hku.hk;

cng@unimelb.edu.au

\begin{abstract}
Mental ill health affects individual well-being and national economic prosperity and makes up a substantial portion of the burden of disease globally, especially in the AsiaPacific region. Integrating mental health into primary care is widely considered a key strategy to improve access to mental health care. Integration, however, is a complex process that needs to be addressed at multiple levels. A collaboration between the Asia-Pacific Economic Cooperation (APEC) Digital Hub for Mental Health and the World Organization of Family Doctors (WONCA) is described in this paper, which outlines a framework and next steps to improve the mental health of communities in APEC economies. This paper notes gaps related to the integration of mental health into primary care across the region and identifies enablers and current best practices from several APEC economies. The potential of digital technology to benefit primary mental health care for populations in the APEC region, including delivery of training programs for healthcare staff and access to resources for patients, is described. Finally, key next steps are proposed to promote enhanced integration into primary care and improve mental health care throughout the APEC region.
\end{abstract}

Keywords: mental health, primary care, Asia Pacific, digital

\section{Introduction and Background \\ Mental Health in the Asia-Pacific Region}

Mental health is vital for health and well-being, as well as social and economic prosperity. ${ }^{1}$ There is extensive literature highlighting the associations between poor mental health, poor physical health outcomes and compromised social well-being. ${ }^{2}$ Economic data also highlight the importance of targeting mental health. ${ }^{3}$ A global return on investment analysis of a scaled-up response to the public health and economic burden of depression and anxiety disorders for the period 2016-2030 across 36 countries has estimated economic benefit-to-cost ratios of 2.3-3.0 to 1, and 3.3-5.7 to 1 when the value of health returns was included. ${ }^{3}$ Financial benefits with such interventions result in part from decreases in overall healthcare costs and increased rates of workforce participation. The World Economic Forum estimates the global cost of chronic diseases at over USD 47 trillion between 2010 and 2030, of which USD 16 trillion is attributed to mental health problems. ${ }^{4}$

Improving access to and availability of mental health care is a global challenge. ${ }^{5,6}$ However, addressing the burden of mental illness is particularly critical in low- and middle-income countries (LMICs). It was estimated that 
LMICs bore $54 \%$ of the global burden of mental health problems in 2010, which is estimated to increase to $58 \%$ in $2030 .^{7}$ The WHO Mental Health Atlas ${ }^{8}$ estimated that less than $2 \%$ of global median health expenditure was on mental health, with a wide difference between spending in high-income countries (HICs) and LMICs, which indicates disparities in the national mental health funding for the delivery of evidence-based mental health care.

The Asia-Pacific Economic Cooperation (APEC) region is an inter-governmental economic organization of 21 Pacific Rim member economies that aims to promote sustainable growth, free trade and economic integration across the region. ${ }^{9}$ The APEC region accounts for $60 \%$ of global gross domestic product, with $39 \%$ of the world's population. ${ }^{10}$ Within the APEC economies (both HICs and LMICs) untreated mental ill health is an important challenge to population health, well-being and prosperity. Mental illness accounts for more than $20 \%$ of total years lost due to disability and $9.3 \%$ of disabilityadjusted life years in the region. ${ }^{11}$ Fewer than half of people with mental illness receive evidence-based, effective treatment. ${ }^{11}$ Therefore, there is an economic and social imperative to promote mental health in the APEC economies. ${ }^{1}$

In 2014, mental health was identified as an important factor in sustainable development across the region. The APEC Roadmap to Promote Mental Wellness in a Healthy Asia Pacific (2014-2020) ["the Roadmap"] was endorsed and implementation of the goals was recommended. These goals are aligned with a broad range of initiatives, ${ }^{7,12}$ diverse in nature and focus on innovation, facilitating public-private engagement, and promoting best practice. These outcomes are aligned with the United Nations Sustainable Development Goals (SDGs), ${ }^{13}$ including SDG 3.4 for health and well-being.

\section{The APEC Digital Hub for Mental Health and WONCA}

The APEC Digital Hub for Mental Health ["the Digital Hub"] was created under the mandate of the Roadmap 9 and acts as the coordinating center for mental health in the Asia Pacific. The goals of the Digital Hub are to enhance awareness, share information and experiences, develop curricula, and facilitate the identification and implementation of evidence-based practice and models to promote mental health and wellness in the Asia Pacific. A strategic needs assessment identified seven key priorities required to meet these goals. ${ }^{14}$ Among these priorities is promoting the integration of mental health into primary care and community-based settings, ${ }^{14}$ which is recognized as a key step in improving mental health care for all. ${ }^{15}$ Activities related to this priority area are coordinated by a work group made up of experts from across the region and led by co-authors $\mathrm{Ng} \mathrm{CH}$ and Lam CLK.

The World Organization of Family Doctors (WONCA) aims to improve the quality of life of people around the globe, promoting high standards of care in family medicine. ${ }^{16}$ WONCA also promotes the adoption of the bio-psychosocial model ${ }^{17}$ for holistic care, reflecting the importance of mental health for individual well-being. WONCA has defined six domains for the core competencies of family doctors in mental health care: values, communication skills, assessment, management, collaboration and referral, and reflective practice. ${ }^{16}$ The Digital Hub and WONCA recognize that a collaborative approach is essential to address challenges facing mental health service improvement. This gave the impetus for both organizations to embark on a partnership, which was launched in Singapore in November 2019, to promote the enhanced integration of mental health into primary care in the APEC region. This article was developed as part of this initiative and key discussions from the November 2019 meeting guided the formation of this publication.

\section{Rationale for Integration of Mental Health into Primary Care}

There is a clear rationale for integrating mental health into primary care based on the APEC Roadmap, ${ }^{9}$ WONCA integration principles ${ }^{18}$ and core competencies. ${ }^{16}$ In the 2008 WHO and WONCA report Integrating Mental Health in Primary Care: A Global Perspective, ${ }^{18}$ principles guiding the promotion of mental health care were advanced, noting that: the burden of mental health is great; mental and physical health problems are interwoven, and the treatment gap for mental health is vast. The report noted that the integration of mental health into primary care was associated with four key benefits: it enhances access, promotes respect for human rights, is affordable and cost-effective, and generates good health outcomes. The benefits of integration have been widely recognized for over a decade. ${ }^{19}$ It is well established that effective primary care services, including primary mental health care, are associated with more equitable distribution of 
health within populations and reductions in the adverse effects of income inequality on health. ${ }^{20,21}$

Mental illnesses are among the leading causes of morbidity and mortality worldwide, with depression ranked by the $\mathrm{WHO}$ as the single largest contributor to global disability and a major contributor to suicide deaths. ${ }^{22}$ It is recognized that optimizing mental health is pivotal to reducing the global burden of non-communicable diseases (NCDs). ${ }^{12}$ In 2018, the WHO expanded their focus on the major four NCDs and risk factors to a five-by-five approach that includes mental disorders and environmental contributors. ${ }^{23}$ Accordingly, mental ill health can be considered as an NCD and should therefore be managed like other NCDs in practice. Specifically, NCD management should involve specialist input and non-specialist case management, with an aim of promoting shared/collaborative care. ${ }^{24,25}$ As the majority of patients with mental health concerns present to primary care, enhancing integration of mental health into primary care is vital in guiding optimal identification, diagnosis and management of patients. ${ }^{26}$ Furthermore, primary care provides comprehensive and person-centered care and can serve as the ideal place to expand mental health care services and programs. ${ }^{20}$

The integration of mental health services into primary care may help to diminish the challenges facing many nations in the provision of mental health care. A key challenge is the human resource gap in LMICs, where there is a shortage of mental health specialists. ${ }^{27}$ While this shortage reflects a complex web of influences, integrating mental health into primary care may mitigate this resource gap. An integrated approach can promote wider access to mental health services for the population, targeting health inequalities. Integration can reduce the concentration of specialist services in urban areas and widen the availability of resources and expertise. ${ }^{2}$ Integrating mental health services into primary care facilitates collaborative care with other health professionals or allied health workers, as well as community-based social and health organizations in enhancing the access and delivery of mental health care and support for those in need. Integration of services with primary care can also promote improved help-seeking for local populations. ${ }^{28}$ Broadening of mental health service access in the community is consistent with the WHO organizational pyramid for optimal mix of services of mental health to meet the diverse needs of a heterogeneous population. ${ }^{29}$ Therefore, integration of mental health into primary care services is key to achieving optimal mental as well as physical health on both a local and global scale.

\section{Challenges for Integration of Mental Health into Primary Care}

Despite increased attention at the level of government and policy, a report by the Lancet Commission on Mental Health and Sustainable Development noted increasing burdens of mental ill health and slow progress, including poor investment on a global level. ${ }^{2}$ These findings highlight numerous challenges of integrating mental health into primary care including training needs, resources and support, stigma and awareness, and the rural-urban divide.

Training needs can have a profound impact on the capacity of service providers to meet the needs of the local population. In HICs, family doctors have mental health training and studies have shown that training is associated with improved knowledge, skills and practices. ${ }^{30,31}$ However, there is a lack of conclusive data regarding the impact of training on patient outcomes. This may reflect a 'know-do' gap, that needs to be addressed to assure the successful implementation of evidence-based practice. In contrast, family doctors and healthcare staff in LMICs may lack or have insufficient training specific to mental health. Improving access to training for family doctors, and other non-specialists (including lay health workers and community-based providers) may help to overcome challenges specific to LMICs. ${ }^{27}$

Resources are particularly important in delivering services and there is evidence to suggest that LMICs in particular face challenges such as poor resources, lack of clear referral pathways, and poor capacity. ${ }^{15}$ However, even in HICs, resources and capacity may be variable on a regional basis, reflecting health inequalities and disparity in service provision. There is also a recognized human resource gap in LMICs, with a lack of mental health specialists relative to the needs of the population. ${ }^{32}$ Targeting resources is a complex process, as even when changes in laws and legislation occur, resources do not always follow. ${ }^{33}$ The use of task-shifting or task-sharing strategies, whereby tasks are shared across professional groups to effectively utilize resources with mental health specialists acting in a supervisory capacity, may result in challenges related to professional boundaries, staff burnout and turnover. ${ }^{34}$

Stigma and awareness can influence the delivery of mental health care. Mental health stigma persists 
throughout all APEC economies and may affect care quality and help-seeking for mental health problems. ${ }^{11}$ Stigma may be present at the level of the general public, as well as within healthcare services, while differences in cultural perceptions of experiences of mental ill health add complexity to the definition of stigma. Low levels of help-seeking, in part due to low mental health awareness and stigma, may affect service uptake and access. ${ }^{33}$ This is symptomatic of wider deficits in mental health literacy in LMICs, where the population may have poor understanding or recognition of mental health disorders as well as poor knowledge of where to seek information on risk factors and treatment for mental health conditions. ${ }^{35}$

Finally, disparities in geographical populations' characteristics, funding and resource access are apparent and serve as barriers to service integration. This is encapsulated in the rural-urban divide noted in the provision and quality of mental health services. ${ }^{33}$ Poor or non-existent rural mental health services and disparities in care have been described in both LMICs and HICs. ${ }^{33}$ Therefore, delivering the integration of services across a region needs to take into account local challenges and inequalities in care provision.

While it is acknowledged that APEC represents one of the most culturally and economically diverse regions in the world with various cultural and structural barriers in different economies, and that tailored approaches are needed to promote the integration of mental health into primary care, based on identified local and regional challenges, there is a paucity of data on barriers specific to the APEC economies. Some common barriers are likely to include those related to training and support for the integration process. Training rollout is piecemeal, reflecting disparities in training provision and quality. There is also little evidence available for the APEC region and a lack of evaluation related to the integration process. Political willingness has the potential to enhance or impede progress. Government interest in the integration of services is gradually increasing but it is likely that there will be a delay between funding and resource provision and the eventual delivery of services. Overall, implementation of the key strategies to promote the integration of mental health into primary care has been slow and limited; a robust infrastructure, with resources, supervision and referral/collaboration is needed to galvanize change.

\section{Principles of Integrating Mental Health into Primary Care}

The need to integrate mental health into primary care is justified and relevant to contemporary needs in the APEC economies. In order to achieve effective integration, conceptual principles need to be translated into operational models, implementation steps and strategies. Optimal integration needs to adapt to the diverse socioeconomic and health system contexts of each member's economy in the APEC region. Additionally, within each member economy, the implementation strategies and targets need to take into account the local context, in order to meet population needs in a feasible, appropriate and sustainable manner.

Markers of successful service integration are diverse, reflecting the complexity of achieving integration in healthcare systems. Firstly, there needs to be a defined presence of mental health team members or service providers based in primary care. This relies on improving the intensity and standard of training in mental health received by primary health care staff, as well as the formal inclusion of mental health in training curricula, particularly for family doctors, and including nurses, psychologists and other allied primary health care professionals. This will improve the identification of individuals with mental health needs and enable these practitioners to provide mental health care and support. Mental health care should be patient-centered, personalized and compassionate; the value of access to empathetic members of the healthcare team cannot be overlooked. In addition, integration relies on the presence of adequate resources for the diagnosis and management of common mental health problems. ${ }^{15}$ The provision of appropriate screening and evidence-based pharmacological and psychosocial treatments is essential. The presence of appropriate and effective referral systems or collaborative arrangements should serve as an important marker for service integration, highlighting the need for a multidisciplinary approach to care. ${ }^{36,37}$

There is a need to build on the principles identified in the $2008 \mathrm{WHO} /$ WONCA report, including updating the evidence base, and aligning with APEC Roadmap strategies for the APEC economies. These principles should be aligned with effective service delivery models to ensure care that is patient-centered, evidence-based, measurement-based, population-based, and accountable. ${ }^{38}$ Here we present the APEC Digital Hub for Mental Health and WONCA collaborative framework, some case examples from the APEC economies, and the next steps for improving the integration of mental health into primary care in the APEC region. 


\section{APEC Digital Hub and WONCA Collaborative Framework for Primary Mental Health Care}

Recognizing the need for the integration of mental health into primary care and a robust effective implementation plan, and the lessons learned from ongoing initiatives as outlined in the case studies, the Digital Hub and WONCA have developed a collaborative framework to promote successful integration in the region. The framework, as described in Table 1, focuses on three principles: engagement (encouraging public and professional participation), enablement (provision of training and tools to equip family doctors and other primary health care workers) and empowerment (confidence and ownership of family doctors and other primary health care staff to integrate mental health care into primary care).

\section{Case Examples from APEC Economies}

Despite an ongoing need to address the gaps in mental health care in the region, there has been notable progress in some areas. Over the past decade, broad changes have been seen in policies and health systems in APEC economies relating to mental health. In 2010, Japan declared mental illness to be one of five priority disease areas. Similar changes have been noted in legislation in other APEC economies: in 2012, China passed a first-ever mental health law and, in 2014, Indonesia modernized legislation on mental health care. These broad changes in legislation reflect an increased recognition of the challenges facing mental health care provision on a national level and the growing burden of mental ill health in APEC economies. Integration of mental health into primary care is a key aspect of contemporary mental health legislation. Evaluation of existing strategies and processes employed in APEC economies may serve as examples for other economies while highlighting the potential for capacity building in the region.

Progress has also been made at the program level, with a number of initiatives taking place to advance the integration of mental health into primary care and communitybased settings. Sharing best practice from the region is helpful as it illustrates model programs that may be adapted and scaled-up for population-level impact. A number of case studies, as shown in Table 2, illustrate ongoing initiatives from the region.

\section{Recommendations for Implementation}

A number of implementation frameworks, including the Promoting Action on Research Implementation in Health Services (PARIHS), the Consolidated Framework for Implementation Research (CIFR) and the Evidence-based System for Innovation Support (EBSIS) frameworks, identify barriers to implementation and emphasize the need for facilitation/implementation support beyond clinical support. ${ }^{43-45}$ The Normalization Process Theory (NPT) is a useful sensitizing tool that addresses key factors required for successful implementation and integration of complex

Table I The Digital Hub and WONCA Collaborative Framework for Integrating Mental Health into Primary Care

\begin{tabular}{|c|c|}
\hline Engage & $\begin{array}{l}\text { - Engage public to recognize and seek help for mental health problems } \\
\text { - Build on the strengths that already exist, including family doctors, community and social networks in supporting mental health } \\
\text { - Utilize digital media and social media to engage the wider public. Create wellness apps and online resources for consumers } \\
\text { - Engage organizations and economies to promote mental health and well-being }\end{array}$ \\
\hline Enable & $\begin{array}{l}\text { - Identify gaps to achieving mental health integration into primary care at the local level to inform targeted strategy development } \\
\text { - Disseminate best practice models, successful tools and evidence-based resources to enable implementation and scale-up } \\
\text { - Create an adaptable, flexible implementation framework that can be adopted and customized to work effectively in the local } \\
\text { realities of APEC economies to experience success } \\
\text { - Develop policies, support, funding, capacity building and curriculum development } \\
\text { - Provide online materials that are accessible at no cost }{ }^{39} \text { and encourage telehealth technology and integrated platforms to assist } \\
\text { clinicians and patients with clinical care } \\
\text { - Enhance training on mental health for all healthcare staff, particularly family doctors and primary care workers. Training may be } \\
\text { provided in online webinar formats for ease of accessibility }\end{array}$ \\
\hline Empower & $\begin{array}{l}\text { - Align with existing policies and resources to recognize the family doctor plays a key role in integrating mental health into primary care } \\
\text { - Unite resources in one place, consider an online repository, to provide tools, such as current best practice and treatment guidelines, that } \\
\text { can be used at the point of primary care to diagnose and treat mental health problems }\end{array}$ \\
\hline
\end{tabular}


Table 2 Case Studies from Across the APEC Region

\begin{tabular}{|c|c|}
\hline $\begin{array}{l}\text { APEC } \\
\text { Economies }\end{array}$ & Case Study Synopses \\
\hline \multicolumn{2}{|c|}{ ENGAGE to promote mental health care } \\
\hline $\begin{array}{l}\text { Canada and } \\
\text { China }\end{array}$ & $\begin{array}{l}\text { Enhanced Measurement-Based Care Effectiveness for Depression (EMBED): A Canada-China Implementation Project } \\
\text { Authors: Raymond Lam, Jun Chen } \\
\text { This initiative aims to adapt and develop technologies including smartphone applications, online training programs, electronic medical records and internet- } \\
\text { delivered self-management interventions with telephone and WeChat (SMS) coaching, to implement measurement-based care (MBC) for depression in } \\
\text { community mental health centers across Shanghai. Technology-enabled MBC tools and training developed through EMBED have the potential to serve as } \\
\text { models for future development and scale up in the region. The first phase of the project, a situational analysis of contextual factors, facilitators and potential } \\
\text { challenges to global mental health, was completed in } 20199^{40} \\
\text { The situational analysis identified several barriers and facilitators at the structural and organizational levels of the Shanghai mental health system and from the } \\
\text { perspectives of clinicians and patients. The results of situational analysis will inform the design and delivery of an implementation strategy for MBC in Phase } 2 \text { of } \\
\text { the study. }\end{array}$ \\
\hline Indonesia & $\begin{array}{l}\text { Healthy Indonesia Through Family Approach Program: Integrating Mental Health into Primary Health Centers } \\
\text { Authors: Irmansyah, Eka Viora, Sri Idaiani } \\
\text { Mental health is included among the } 12 \text { health indicators of Healthy Indonesia through the Program Indonesia Sehat melalui Pendekatan Keluarga } \\
\text { (PIS-PK). The } 12 \text { indicators cover child and maternal health, common diseases, sanitation, healthy behaviors and insurance coverage. } \\
\text { As of January 2020, almost } 44.5 \text { million families (54\%) have been assessed. } 36 \% \text { of people with serious mental illness had adequate treatment } \\
\text { compared to January 2018, when only 15\% of people with serious mental illness had adequate treatment. Integrating mental health in PIS-PK has } \\
\text { successfully increased mental health awareness, service provision in primary care including treatment for those with serious mental illness. }\end{array}$ \\
\hline \multicolumn{2}{|c|}{ ENABLE to promote mental health care } \\
\hline Chile & $\begin{array}{l}\text { Implementation of the Screening, Brief Intervention and Referral to Treatment for Alcohol, Tobacco and Substance Use (DIR) } \\
\text { Program in Chile } \\
\text { Authors: Matias Irarrázaval Dominguez, Pablo Norambuena, Milena Pereira } \\
\text { The DIR program is a nationally funded program through which teams of health professionals and trained technicians carry out screening through validated } \\
\text { tools and deliver mental health and substance misuse interventions stratified according to risk in primary care. } \\
\text { The DIR model has been adapted to be implemented using digital technologies. Remote interventions include email, web platforms, mobile applications, } \\
\text { video calls, telephone calls and telephone messages. Telephone calls are the most available in the current context. Remote interventions as part of DIR, } \\
\text { particularly phone calls, can be effective and especially cost-effective. } \\
\text { In } 2019 \text {, the program was implemented in } 50.4 \% \text { of communes and to } 87 \% \text { of the population under health monitoring. I,509, II } 5 \text { screens were applied, with } \\
88,585 \text { brief interventions and } 26,869 \text { assisted referrals for substance misuse treatment. The budget was } 3,200,190 \text { USD and } 4000 \text { professional and non- } \\
\text { professional workers were trained. The program will be expanded to reach all communes, increasing coverage among young people and men and the impact } \\
\text { evaluated. }\end{array}$ \\
\hline Peru & $\begin{array}{l}\text { Mental Health Reform in Peru: Community Mental Health Services } \\
\text { Author: María Sofía Cuba Fuentes } \\
\text { Poor infrastructure and lack of health resources remain key challenges in Peru. } \\
\text { In } 2014 \text {, the Ministry of Health and the Ministry of Economy of Peru approved "Control and Prevention in Mental Health", a a mental health } \\
\text { program allocating } 20 \text { million USD for the implementation of Community Mental Health Centers (CMHC) in Lima and } 6 \text { regions. }{ }^{42} \\
\text { The CMHCs, staffed by psychiatrists, family doctors and community psychologists/therapists, received referrals from primary care and delivered } \\
\text { a range of multidisciplinary services. } \\
\text { The reform increased access to community mental health care. In } 2012 \text { only II\% of people with a mental disorder received care compared with } \\
26 \% \text { in } 2018 \text {. Furthermore, in areas where CMHCs were implemented, the number of people seen for mental ill health concerns increased by } 229 \% \\
\text { vs } 36 \% \text { in areas without CMHCs. } \\
\text { The implementation of CMHCs has also strengthened integration with primary care and reduced the mental health care burden on general and } \\
\text { psychiatric hospitals. }\end{array}$ \\
\hline
\end{tabular}

(Continued) 
Table 2 (Continued).

\begin{tabular}{|c|c|}
\hline $\begin{array}{l}\text { APEC } \\
\text { Economies }\end{array}$ & Case Study Synopses \\
\hline Vietnam & $\begin{array}{l}\text { Delivery and Scale-Up of Community-Based Depression Care in Vietnam } \\
\text { Authors: Vu Cong Nguyen, John O'Neil, Jill Murphy, Leena Chau, Harry Minas } \\
\text { Researchers from Vietnam, Canada and Australia tested a supported self-management (SSM) intervention for depression in Vietnam. } \\
\text { The intervention involved screening adults for depression in primary care settings, with identified patients referred to a social collaborator (SC), } \\
\text { a community-based informal provider working in the social services sector. SCs provided coaching utilizing an Antidepressant Skills Workbook over } \\
\text { a two-month period. } \\
\text { SSM was effective in reducing depression in community-based settings. A key success factor was the collaboration with the Vietnamese Ministry } \\
\text { of Labour, Invalids and Social Affairs (MOLISA). Digital delivery via a mobile phone app may help to address access and sustainability concerns, } \\
\text { promoting effective scale-up. }\end{array}$ \\
\hline \multicolumn{2}{|c|}{ EMPOWER to promote mental health care } \\
\hline Japan & $\begin{array}{l}\text { Train the Trainers } \\
\text { Authors: Ryuki Kassai, Chris Dowrick, Cindy L.K. Lam, Garth Manning } \\
\text { The } 201 \text { I Great East Japan Earthquake and nuclear accident revealed the need for better community mental health care. The WONCA Working } \\
\text { Party for Mental Health with the International Association for Communication in Healthcare, organized an international task force to create } \\
\text { a "Train the Trainers" program for improving depression care. This comprised two week-long workshops, six months apart, for family medicine } \\
\text { educators in Fukushima, Japan } 2018 \text {. } \\
\text { Digital technology was utilized and involved monthly follow-up webinars ( } 5 \text { times between } 2 \text { in-person workshops } 6 \text { months apart), where the } \\
\text { participants (trainers) were able to ask the task force for expertise and feedback to deepen their understanding of the subjects and to improve their } \\
\text { local cascading education activities. } \\
\text { The program expanded to include attendees from across Asia Pacific with workshops at WONCA World } 2018 \text { and Asia Pacific Regional } 2019 \\
\text { conferences. } \\
\text { Key success factors include a dedicated task force, follow-up webinars, cascading education model, international collaboration and financial } \\
\text { support. }\end{array}$ \\
\hline New Zealand & $\begin{array}{l}\text { New Tools for GPs Treating Depression: Coaches and Online Self-Help } \\
\text { Authors: Vanessa Cooper, Penny Marlowe, Anil Thapliyal } \\
\text { The Journal eCoaching Service is a digital program to support people with depression and/or anxiety. The Service utilizes an existing online self- } \\
\text { help program, The Journal (part of the National Depression Initiative in New Zealand), and coaching from peers or health coaches via phone and } \\
\text { text messages. } \\
\text { Key success factors include ease of referral through embedding the form into practice management systems in primary care and the peer-support } \\
\text { background of the eCoaches. The service is provided free with easy accessibility, no wait times, convenient delivery from people's own homes and } \\
\text { self-directed care with wraparound support. }\end{array}$ \\
\hline
\end{tabular}

Note: aDIR, in Spanish, "Detección, Intervenciones Breves y Referencia Asistida".

interventions and technologies into routine practice and aids the identification of factors inhibiting or encouraging such implementation. ${ }^{46}$ The use of the NPT is recommended.

The recommendations for implementation of strategies to promote the integration of mental health into primary care are aligned with the APEC Digital Hub and WONCA collaborative framework (Engage, Enable, Empower). These recommendations include identifying relevant stakeholders involved in implementation, improving mental health awareness, ensuring the infrastructure and resources needed to facilitate implementation are in place, and identifying clear indicators for monitoring and evaluating implementation.

\section{Recommendation \#I- Identify Relevant Stakeholders}

Stakeholders are diverse and need to be clearly defined and targeted, with a key focus on family doctors serving as primary care team leaders and cross-disciplinary care coordinators; it is recognized that in some APEC economies there is a lack of access to a family doctor, and other health professionals such as registered nurses or community health leaders may need to take on this role. This coordination role should involve liaison with other stakeholders, including staff involved in medical education, members of the primary care team, associated professionals and specialists. There is added value in recognizing 
the role of people with lived experience of mental health services, patient advocates, family members and community leaders in service integration planning. ${ }^{47}$ Ultimately, mental health care reflects a personal patient journey and the impact of strengthening the quality and quantity of human interactions during care provision can be profound. Appreciation of patient perspectives and frontline care staff is essential to drive positive, patient-centered services. Therefore, a broad range of stakeholders are recognized in this context. All stakeholders should be engaged by raising awareness of mental health partnerships and strategies on a national level, with support from training programs and professional bodies, and empowerment through the development of confidence and competence in mental health care. Stakeholders should also be engaged with the design and production of interventions. ${ }^{48}$ Such co-design, or co-production, may be enhanced by having patient groups as well as clinicians as partners in the process, co-creating trustworthy and practical knowledge.

\section{Recommendation \#2- Improve Mental Health Awareness}

All stakeholders will benefit from initiatives to improve mental health awareness, including targeted strategies to improve mental health literacy, while health and social care staff should have specific knowledge of diagnostic features of mental disorders and treatment pathways available in the region. There is a need to encourage family members to be aware of mental ill health, symptoms and signs, as this may promote earlier diagnosis and treatment of mental health conditions, reduce stigma and promote help-seeking. ${ }^{49}$ De-stigmatization of mental health conditions is a priority, with champions promoting specific campaigns and strategies to raise awareness and ensure the dissemination of accurate mental health information. These initiatives must include structured policy intervention, as systemic discrimination and stigmatization are highly embodied at structural levels of societies, and within healthcare settings. The role of the media in raising awareness and in educating the general public on mental health should also be harnessed through stakeholder collaborations. ${ }^{50,51}$

\section{Recommendation \#3- Ensure Necessary Infrastructure and Resources are in Place} Infrastructure and resources are needed to ensure implementation is effective. These considerations include the time and finances underlying implementation processes, budgets for treatment costs particularly medication and therapeutics, the policies and healthcare systems influencing population care, and the need for supportive resources. Distribution and allocation of resources must consider non-urban contexts as people living in rural communities tend to be the most neglected groups. Long-term political commitment for ensuring the allocation of resources for the mental health field is a priority and sustainable funding for mental health must be established independent of the elected government. From a financial perspective, there is a need to align reimbursement structures to deliver mental health services in the primary care setting. Education and focused resources to support care need to be evidence-based and developed with the involvement of key opinion leaders and in consultation with family doctors. Identifying and empowering champions of mental health may also provide opportunities to support the development of the professional mindset. Curricula, policies, guidelines, healthcare system-wide coordination and relevant cross-sectoral collaboration (eg social services, education) are required to facilitate comprehensive implementation. There is a need for a redesign in curricula for healthcare degrees, with mental health included in continuing medical education and the inclusion of formal training during residency. Family doctors should be key stakeholders in curriculum redesign and in the formulation of guidelines and policy relating to mental health integration. Digital technology can facilitate the implementation process.

\section{Recommendation \#4- Identify Clear Implementation Indicators for Short, Medium and Long-Term Success}

Different evidence-based interventions should be evaluated in real-world primary care to see their effectiveness, cost-effectiveness and their potential for escalation. Mental health problems are closely linked to other social malaises such as lack of access to housing, lack of basic income support, lack of treatment coverage, lack of resources to meet basic needs, such as food security or to escape gender and race discrimination, or intimate partner violence. Further, building on paired mental health services with existing local primary care or community-based health support programs that work well could also help to assess the effects of the integration of mental health care services with other social or health programs. 
The integration of services is a process, not an event. ${ }^{18}$ Consequently, there is a need to ensure that key deliverables and outcomes are monitored over time and reflect specific, measurable, achievable, relevant and time-based goals. ${ }^{52}$ Assigning appropriate outcome indicators and deliverables to the implementation process is critical in guiding service development. The WHO Mental Health Atlas $^{8}$ indicators of mental health may provide a framework for evaluating care outcomes. The Economist Intelligence Unit (EIU) ${ }^{33}$ paper also identified 18 indicators specific to the integration of mental health and existing services, based on the environment, opportunities, access to treatment and governance. These indicators included deinstitutionalization, family and carer support, access to therapy and medication, human rights protection and cross-cutting policies.

It is suggested that relevant indicators should include the number of people who have received training in mental health care, access to drug and psychosocial treatments, the availability of supervision, the existence of referral routes and infrastructure/resources conducive to confidential consultations. There is a need to consider the equitable provision of mental health care, given the range of health inequalities noted in APEC economies. ${ }^{53}$ Indicators reflecting equity, access for the most vulnerable members of society, and the sociocultural acceptability of care provision should also be considered. Perspectives of both family doctors and patients should be emphasized within indicators of integration, including aspects of the patient experience and perceptions of help-seeking and evaluation of self-efficacy, knowledge and skills among family doctors and other healthcare staff.

\section{The Role of Digital Technology}

Digital technology may help to facilitate integrating mental health into primary care. The role of digital technology is greatly increasing in society and within healthcarespecific contexts, permitting coordination of care and more rapid dissemination of information. ${ }^{54}$ It is recognized that digital technology can facilitate the integration of mental health into primary care in a number of ways.

There is evidence to support the use of technology to enhance measurement-based care effectiveness. ${ }^{55,56}$ Technology can be used in the promotion, screening, diagnosis and treatment of mental health problems. When implemented effectively, digital technology provides an opportunity to collect robust healthcare data and to permit standardization of that data, improving the reliability of data sets and associated evaluation processes. ${ }^{57}$ Digital technology can play a very important role in providing implementation support to healthcare providers by providing performance feedback and helping in problem-solving remotely. ${ }^{58}$

Digital technology has the potential to increase access to training programs for healthcare staff, particularly through online delivery of content. Digital technology may also be used to increase support for primary care from specialists to facilitate task-sharing, particularly in rural settings, as well as facilitating multidisciplinary care. ${ }^{34}$ The same benefits may also be realized in patients with mental health conditions, whereby technology can facilitate access to support and resources, potentially improving self-management, ${ }^{1}$ improving access for people living in rural, remote or underserved areas, and promoting equity in mental health care. Expansion of interest and investment in internet services in rural communities are essential. However, it must be recognized that digital technology cannot replace therapeutic relationships and that patients mostly prefer face-to-face care when possible. ${ }^{59}$

Finally, digital technology may be more widely used as a means of disseminating information and promoting awareness and education. Anti-stigma messaging, improvements in mental health literacy and improved awareness of local resources may be achieved through digital technology. ${ }^{59}$ Therefore, embracing the opportunities associated with digital technology has the potential to benefit the mental health care of the populations in the APEC economies.

\section{Next Steps}

The collaborative framework and recommendations outlined in this paper act as a resource to inform the implementation of integration of mental health into primary care, which can in turn be adapted to the local context of service delivery.

To facilitate the integration of mental health into primary care:

- Policymakers must demonstrate leadership and commitment to enable progress on integration.

- Family doctors and other key stakeholders have a role to play as advocates for improved funding, training and infrastructure for mental health integration into primary care.

- Investment in awareness-raising initiatives is needed.

- Strategies should be aligned with existing global initiatives such as the SDGs. 
- Local realities should be appreciated and used to guide implementation of service integration, building on existing capacity and strengths to provide contextually appropriate care.

- De-stigmatization at the level of service provider and the health system is needed to improve access to services and care quality.

- Health service development, whereby WONCA core competencies of mental health care are embedded in family practice should be combined with social development, economic development and sustainable development approaches.

- Digital technology should be developed and deployed according to local needs and feasibility; barriers to uptake of digital technology should be addressed at a local level.

- The value of human interactions and personalized care in the context of mental health and well-being must always be remembered.

\section{Abbreviations}

APEC, Asia-Pacific Economic Cooperation; CMHC, Community Mental Health Centers; DIR, Detección, Intervenciones Breves y Referencia Asistida; HICs, highincome countries; LMICs, low- and middle-income countries; MBC, measurement-based care; MOLISA, Ministry of Labour, Invalids and Social Affairs; NCDs, noncommunicable diseases; PIS-PK, Program Indonesia Sehat melalui Pendekatan Keluarga; SC, social collaborator; SDGs, Sustainable Development Goals; SSM, supported selfmanagement; The Digital Hub, APEC Digital Hub for Mental Health; WONCA, World Organization of Family Doctors.

\section{Data Sharing Statement}

Not applicable.

\section{Ethics Approval and Consent to Participate}

Not applicable.

\section{Consent for Publication}

Not applicable.

\section{Acknowledgments}

The authors acknowledge Innovaacom LLC for editorial support in the preparation of this manuscript with funding from Pfizer Medical Grants.

\section{Author Contributions}

All authors made a significant contribution to the work reported, whether that is in the conception, study design, execution, acquisition of data, analysis and interpretation, or in all these areas; took part in drafting, revising or critically reviewing the article; gave final approval of the version to be published; have agreed on the journal to which the article has been submitted; and agree to be accountable for all aspects of the work.

\section{Funding}

This work was supported by an independent medical education grant from Upjohn, a division of Pfizer. The medical education grant provided funding for the working group meeting and editorial assistance in the development of the manuscript. Neither honoraria nor payments were made for authorship.

\section{Disclosure}

Dowrick C. has nothing to disclose. Kassai R. has nothing to disclose. Lam CLK. has nothing to disclose. Lam RW. reports personal fees from Allergan, Lundbeck Institute, Hansoh, Otsuka, Canadian Network for Mood \& Anxiety Treatments, and Myriad Neuroscience; grants from AsiaPacific Economic Cooperation, grants from VGH-UBCH Foundation, BC Leading Edge Endowment Fund, and St. Jude Medical; and grants and personal fees from Janssen, Lundbeck, and Pfizer, outside the submitted work. Manning G. has nothing to disclose. Murphy J. reports grants from MITACS outside the submitted work. $\mathrm{Ng} \mathrm{CH}$. reports travel support and honorarium for delivery of talks from Pfizer, Lundbeck and Janssen outside the submitted work. Thuraisingham C. has nothing to disclose. Lam RW. and Murphy J. report no other potential conflicts of interest for this work.

\section{References}

1. APEC Digital Hub for Mental Health. Interim report on the post-2020 vision for mental health and wellness in the Asia Pacific [Internet]. Vancouver, BC, Canada: The APEC Digital Hub for Mental Health; 2019. Available from: https://mentalhealth.apec.org/sites/default/files/ APEC $\% 20$ Digital $\% 20 \mathrm{Hub} \% 20$ for $\% 20$ Mental $\% 20$ Health $\% 20$ Interim $\%$ 20Report\%202020.pdf. Accessed Sep 12, 2020

2. Patel V, Saxena S, Lund C, et al. The lancet commission on global mental health and sustainable development. Lancet Lond Engl. 2018;392(10157):1553-1598. doi:10.1016/S0140-6736(18)31612-X

3. Chisholm D, Sweeny K, Sheehan P, et al. Scaling-up treatment of depression and anxiety: a global return on investment analysis. Lancet Psychiatry. 2016;3(5):415-424. doi:10.1016/S2215-0366(16)30024-4 
4. Bloom D, Cafiero E, Jané-Llopis E, et al. The global economic burden of noncommunicable diseases [Internet]; 2011 Sep. Available from: https:// www.researchgate.net/publication/262935586_The_Global_Economic Burden_of_Noncommunicable_Diseases. Accessed Sep 12, 2020.

5. Patel V, Araya R, Chatterjee S, et al. Treatment and prevention of mental disorders in low-income and middle-income countries. Lancet. 2007;370 (9591):991-1005. doi:10.1016/S0140-6736(07)61240-9

6. Patel V, Belkin GS, Chockalingam A, Cooper J, Saxena S, Unützer J. Grand challenges: integrating mental health services into priority health care platforms. PLOS Med. 2013;10(5):e1001448. doi:10.1371/journal.pmed.1001448

7. World Bank/World Health Organization. Out of the shadows: making mental health a global development priority [Internet]. Washington, DC: World Bank Group; 2016. Available from: https:/www.who.int/mental_health/advocacy/ wb_background paper.pdf?ua=1. Accessed Sep 12, 2020. p. 28.

8. World Health Organization, editor. WHO Mental Health Atlas 2017. Geneva, Switzerland: World Health Organization; 201862 p.

9. APEC. APEC roadmap to promote mental wellness in a healthy Asia pacific (2014-2020). [Internet]; 2014. Available from: https://mental health.apec.org/sites/default/files/APEC_Roadmap_to_Promote Mental_Wellness_in_a_Healthy_Asia_Pacific_2014-2020_1.pdf. Accessed Sep 11, 2020.

10. APEC Secretariat APSU. APEC in charts 2017 [Internet]; 2017 Nov. Available from: https:/www.apec.org/Publications/2017/11/APEC-in -Charts-2017. Accessed Sep 12, 2020.

11. $\mathrm{Ng} \mathrm{CH}$. Mental health and integration in Asia Pacific. BJPsych Int. 2018;15(4):76-79. doi:10.1192/bji.2017.28

12. World Health Organization. Comprehensive mental health action plan 2013-2020 [Internet]. World Health Organization; 2013. Available from: http://www.who.int/mental_health/action_plan_2013/en/. Accessed Sep 12, 2020.

13. Rosa W, editor. Transforming Our World: The 2030 Agenda for Sustainable Development. In: A New Era in Global Health: Nursing and the United Nations 2030 Agenda for Sustainable Development. New York, NY: Springer Publishing Company; 2017. Available from: http://connect.springerpub.com/lookup/doi/10.1891/ 9780826190123.ap02. Accessed Sep 12, 2020. 530-568

14. APEC. APEC mental health initiative. Report on strategic needs in mental health [Internet]; 2016. Available from: https://mentalhealth. apec.org/sites/default/files/APEC_Report_on_Strategic_Needs_in Mental_Health_Final-3.pdf. Accessed Sep 11, 2020.

15. Lund $\overline{\mathrm{C}}$, Tomlinson $\mathrm{M}$, Patel V. Integration of mental health into primary care in low- and middle-income countries: the PRIME mental healthcare plans. Br J Psychiatry. 2016;208(Suppl 56):s1-3. doi:10.1192/bjp.bp.114.153668

16. World Organisation of National Colleges, Academies and Academic Associations of General Practitioners/Family Physicians. Core competencies of family doctors in primary mental health care [Internet]; 2018. Available from: https://www.wonca.net/site/DefaultSite/filesys tem/documents/Groups/Mental\%20Health/Core\%20competencies $\%$ 20January\%202018.pdf. Accessed Sep 11, 2020.

17. Engel GL. The biopsychosocial model and the education of health professionals. Ann N Y Acad Sci. 1978;21(310):169-187. doi:10.1111/j.1749-6632.1978.tb22070.x

18. World Health Organization, World organisation of national colleges, academies and academic associations of general practitioners/family physicians, editors. integrating mental health into primary care: a global perspective [Internet]. Geneva, Switzerland: London: World Health Organization; WONCA; 2008. Available from: https://www.who.int/men tal_health/policy/Integratingmhintoprimarycare2008_lastversion.pdf?ua= 1. Accessed Nov 9, 2020. 206 p.

19. Weltgesundheitsorganisation, editor. Mental health: new understanding, new hope [Internet]. repr. Geneva: World Health Organization; 2002. 178 p. (The world health report). Available from: https://www.who.int/whr/ 2001/en/whr01_en.pdf?ua=1. Accessed October 31, 2020.
20. Starfield B, Shi L, Macinko J. Contribution of primary care to health systems and health. Milbank Q. 2005;83(3):457-502. doi:10.1111/ j.1468-0009.2005.00409.x

21. Shi L. The impact of primary care: a focused review. Scientifica. 2012;2012:432892. doi:10.6064/2012/432892

22. World Health Organization. Depression and other common mental disorders: global health estimates [Internet]. Geneva: World Health Organization; 2017. Available from: https:/www.who.int/publications-detail-redirect/depressionglobal-health-estimates. Accessed Sep 16, 2020. 24 p.

23. World Health Organization. Heads of state commit to lead response to beat noncommunicable diseases, promote mental health [Internet]; 2018. Available from: https://www.who.int/news-room/detail/27-09-2018heads-of-state-commit-to-lead-response-to-beat-noncommunicablediseases-promote-mental-health. Accessed Sep 14, 2020.

24. Ngo VK, Rubinstein A, Ganju V, et al. Grand challenges: integrating mental health care into the non-communicable disease agenda. PLoS Med. 2013;10:5.

25. Stein DJ, Benjet C, Gureje O, et al. Integrating mental health with other non-communicable diseases. BMJ. 2019;28(364):1295. doi:10.1136/bmj.1295

26. Kilbourne AM, Beck K, Spaeth-Rublee B, et al. Measuring and improving the quality of mental health care: a global perspective. World Psychiatry. 2018;17(1):30-38. doi:10.1002/wps.20482

27. Ng CH, Goodenow MM, Greenshaw AJ, Upshall P, Lam RW. Inclusion of mental health in global economic development. BJPsych Int. 2018;15(4):74-76. doi:10.1192/bji.2017.23

28. Rebello TJ, Marques A, Gureje O, Pike KM. Innovative strategies for closing the mental health treatment gap globally. Curr Opin Psychiatry. 2014;27(4):308-314. doi:10.1097/YCO.0000000000000068

29. World Health Organization. Improving health systems and services for mental health [Internet]. World Health Organization; 2009. Available from: https://apps.who.int/iris/bitstream/handle/10665/44219/ 9789241598774_eng.pdf?sequence=1. Accessed Sep 14, 2020. 104 p.

30. Ayano G, Assefa D, Haile K, et al. Mental health training for primary health care workers and implication for success of integration of mental health into primary care: evaluation of effect on knowledge, attitude and practices (KAP). Int J Ment Health Syst. 2017;11:63. doi:10.1186/s13033-017-0169-8

31. Lam TP, Sun KS, Piterman L, et al. Impact of training for general practitioners on their mental health services: the Hong Kong experience. Aust $J$ Gen Pract. 2018;47(8):550-555. doi:10.31128/AJGP-01-18-4478

32. Kakuma R, Minas H, van Ginneken N, et al. Human resources for mental health care: current situation and strategies for action. Lancet Lond Engl. 2011;378(9803):1654-1663. doi:10.1016/S0140-6736(11)61093-3

33. The Economist Intelligence Unit. Mental health integration: provision for supporting people with mental illness: a comparison of 15 Asia Pacific countries [Internet]. The Economist; 2016. Available from: https://eiuperspectives.economist.com/sites/default/files/Mental_ health_and_integration.pdf. Accessed Sep 14, 2020. p. 55.

34. Hoeft TJ, Fortney JC, Patel V, Unützer J. Task sharing approaches to improve mental health care in rural and other low resource settings: a systematic review. J Rural Health off J Am Rural Health Assoc Natl Rural Health Care Assoc. 2018;34(1):48-62. doi:10.1111/jrh.12229

35. Petersen I, Lund C, Stein DJ. Optimizing mental health services in low-income and middle-income countries. Curr Opin Psychiatry. 2011;24(4):318-323. doi:10.1097/YCO.0b013e3283477afb

36. Ehrlich C, Chester P, Kendall E, Crompton D. Implementing new models of integrated mental health care: what impacts effective performance? Int J Integr Care. 2017;17(3):77. doi:10.5334/ijic.3189

37. Goodrich DE, Kilbourne AM, Nord KM, Bauer MS. Mental health collaborative care and its role in primary care settings. Curr Psychiatry Rep. 2013;15(8):383. doi:10.1007/s11920-013-0383-2

38. Bauer AM, Thielke SM, Katon W, Unützer J, Areán P. Aligning health information technologies with effective service delivery models to improve chronic disease care. Prev Med. 2014;66:167-172. doi:10.1016/j.ypmed.2014.06.017 
39. World Health Organization. WHO | WHO Mental Health Gap Action Programme (mhGAP) [Internet]. WHO. World Health Organization. Available from: http://www.who.int/mental_health/mhgap/en/. Accessed Oct 8, 2020.

40. Murphy JK, Michalak EE, Colquhoun H, et al. Methodological approaches to situational analysis in global mental health: a scoping review. Glob Ment Health [Internet. 2019;6.

41. Ministerio de Economía y Finanzas. Programa Presupuestal 0131: control y Prevención en salud Mental [Internet]. Lima: MEF; 2014. Available from: https://www.mef.gob.pe/contenidos/presu_publ/ppr/ prog_presupuestal/articulados/0131_control_prevencion_salud_men tal.pdf. Accessed Sep 14, 2020.

42. Castillo-Martell H, Cutipé-Cárdenas Y. Implementación, resultados iniciales y sostenibilidad de la reforma de servicios de salud mental en el Perú, 2013-2018. Rev Peru Med Exp Salud Publica. 2019;36 (2):326-333. doi:10.17843/rpmesp.2019.362.4624

43. Harvey G, Kitson A. PARIHS revisited: from heuristic to integrated framework for the successful implementation of knowledge into practice. Implement Sci IS. 2016;11:33. doi:10.1186/s13012-0160398-2

44. Damschroder LJ, Aron DC, Keith RE, Kirsh SR, Alexander JA, Lowery JC. Fostering implementation of health services research findings into practice: a consolidated framework for advancing implementation science. Implement Sci IS. 2009;4:50. doi:10.1186/17485908-4-50

45. Wandersman A, Chien VH, Katz J. Toward an evidence-based system for innovation support for implementing innovations with quality: tools, training, technical assistance, and quality assurance/quality improvement. Am J Community Psychol. 2012;50(3-4):445-459. doi:10.1007/s10464-012-9509-7

46. Murray E, Treweek S, Pope C, et al. Normalisation process theory: a framework for developing, evaluating and implementing complex interventions. BMC Med. 2010;8:63. doi:10.1186/1741-7015-8-63

47. Wallcraft J, Amering M, Freidin J, et al. Partnerships for better mental health worldwide: WPA recommendations on best practices in working with service users and family carers. World Psychiatry. 2011;10(3):229-236. doi:10.1002/j.2051-5545.2011.tb00062.x

48. Reeve J, Cooper L, Harrington S, Rosbottom P, Watkins J. Developing, delivering and evaluating primary mental health care: the co-production of a new complex intervention. BMC Health Serv Res. 2016;16(1):470. doi:10.1186/s12913-016-1726-6
49. Han J, Batterham PJ, Calear AL, Randall R. Factors influencing professional help-seeking for suicidality. Crisis. 2018;39 (3):175-196. doi:10.1027/0227-5910/a000485

50. Kakuma R, Kleintjes S, Lund C, et al. Mental health stigma: what is being done to raise awareness and reduce stigma in South Africa? Afr J Psychiatry. 2010;13(2):116-124. doi:10.4314/ajpsy.v13i2.54357

51. Niederkrotenthaler T, Reidenberg DJ, Till B, Gould MS. Increasing help-seeking and referrals for individuals at risk for suicide by decreasing stigma: the role of mass media. Am J Prev Med. 2014;47(3Suppl 2):S235-243. doi:10.1016/j.amepre.2014.06.010

52. Krist AH, Phillips SM, Sabo RT, et al. Adoption, reach, implementation, and maintenance of a behavioral and mental health assessment in primary care. Ann Fam Med. 2014;12(6):525-533. doi:10.1370/ afm. 1710

53. Minas H, Izutsu T, Tsutsumi A, Kakuma R, Lopez AD. Asia-pacific ready to act on mental health target in the SDGs. Lancet Psychiatry. 2015;2(3):199-201. doi:10.1016/S2215-0366(14)00124-2

54. Raviola G, Naslund JA, Smith SL, Patel V. Innovative models in mental health delivery systems: task sharing care with non-specialist providers to close the mental health treatment gap. Curr Psychiatry Rep. 2019;21(6):44. doi:10.1007/s11920-019-1028-x

55. Harding KJK, Rush AJ, Arbuckle M, Trivedi MH, Pincus HA. Measurement-based care in psychiatric practice: a policy framework for implementation. $J$ Clin Psychiatry. 2011;72(8):1136-1143. doi:10.4088/JCP.10r06282whi

56. Fortney JC, Unützer J, Wrenn G, et al. A tipping point for measurement-based care. Psychiatr Serv Wash DC. 2017;68 (2):179-188. doi:10.1176/appi.ps.201500439

57. Hollis C, Morriss R, Martin J, et al. Technological innovations in mental healthcare: harnessing the digital revolution. Br J Psychiatry J Ment Sci. 2015;206(4):263-265. doi:10.1192/bjp.bp.113.142612

58. Muke SS, Shrivastava RD, Mitchell L, et al. Acceptability and feasibility of digital technology for training community health workers to deliver brief psychological treatment for depression in rural India. Asian $J$ Psychiatry. 2019;45:99-106. doi:10.1016/j. ajp.2019.09.006

59. May C, Gask L, Atkinson T, Ellis N, Mair F, Esmail A. Resisting and promoting new technologies in clinical practice: the case of telepsychiatry. Soc Sci Med 1982. 2001;52(12):1889-1901.
Journal of Multidisciplinary Healthcare

\section{Publish your work in this journal}

The Journal of Multidisciplinary Healthcare is an international, peerreviewed open-access journal that aims to represent and publish research in healthcare areas delivered by practitioners of different disciplines. This includes studies and reviews conducted by multidisciplinary teams as well as research which evaluates the results or conduct of such teams or healthcare processes in general. The journal

\section{Dovepress}

covers a very wide range of areas and welcomes submissions from practitioners at all levels, from all over the world. The manuscript management system is completely online and includes a very quick and fair peer-review system. Visit http://www.dovepress.com/testimonials. php to read real quotes from published authors. 